\title{
Diversidad y segregación de nichos en anfibios de montaña en la Reserva La Forzosa (Anorí, Antioquia, Colombia)
}

\author{
Paul David Alfonso Gutiérrez-Cárdenas
}

\begin{abstract}
Resumo
El norte de la Cordillera Central de los Andes Colombianos alberga una fauna diversa de anuros pobremente conocida y altamente amenazada por los procesos intensivos de modificación de bosques. Esta acción antrópica esta creando hábitats distintos, los cuales pueden diferir en la composición de especies y sus abundancias. En un estudio de un año en La Reserva La Forzosa (municipio de Anorí, Antioquia) se investigó las diferencias en la riqueza, composición y abundancia de dos ensambles de anuros presentes en dos bosques premontanos continuos (bosque primario muy intervenido y bosque rastrojo alto) que difirieron
\end{abstract} en su estructura vegetal (complejidad y heterogeneidad) con el bosque menos perturbado mostrando vegetación arbórea mas variable pero vegetación herbácea más homogénea. Aunque no se encontraron diferencias en la riqueza de especies (14 spp. cada uno), el bosque menos perturbado fue más diverso por la mayor equitatividad de las especies; el otro bosque fue más dominado por dos especies (Eleutherodactylus factiosus y E. viejas). En general, la fauna de anuros en la zona estuvo dominada por especies del género Eleutherodactylus y centrolenidos, lo cual es un patrón típico de los bosques Andinos, presumiblemente debido a la relativa ausencia de cuerpos de agua lénticos, pero presencia de quebradas. Se investigaron tres ejes del nicho (tiempo de actividad y uso de hábitats y microhábitats) con un análisis de pseudocomunidades (modelo nulo) con el fin de examinar la segregación ecológica de las especies de anuros que componen el ensamble (sin importar los tipos de bosques). Los tiempos de actividad fueron altamente traslapados entre la mayoría de especies, con más especies activas durante la noche, y unas pocas estrictamente diurnas (Ranitomeya opisthomelas y E. mantipus) u ocasionalmente diurnas. Respecto al hábitat y microhábitat, tampoco se encontró una segregación espacial clara y por eso el análisis de modelos nulos no mostró diferencias significativas entre las especies, aunque había una leve distinción entre especies diurnas que habitan estrictamente en la hojarasca y especies principalmente nocturnas que utilizan los estratos aéreos. Las especies del interior del bosque fueron más generalistas que las especies riparias. Sin embargo, en ambos grupos se encontraron amplios solapamientos en el uso de hábitats. En conclusión, las especies de anuros en este ensamble están usando los recursos cuantificados sin evidencia de efectos de una competencia interespecífica por ellos.

Palavras-chave: Antioquia, Anura, bosque andino, Colombia, Cordillera Central, hábitat, microhábitat, segregación de nichos, uso de recursos espaciales, riqueza de especies

Gutiérrez Cárdenas, Paul David Alfonso.

2005.

Diversidad y segregación de nichos en anfibios de montaña en la Reserva La Forzosa (Anorí, Antioquia).

43 p.

Tesis Maestría Bosques y Conservación Ambiental, Universidad Nacional de Colombia, sede Medellín, Colombia.

1. Antioquia 2. Anura 3. Bosque andino 4. Colombia 5. Cordillera Central 6. Hábitat 7. Microhábitat 8. Segregación de nichos 9. Uso de recursos espaciales 10. Riqueza de especies

I. Universidad Nacional de Colombia, sede Medellín. Departamento de Ciencias Forestales. Posgrado en Bosques y Conservación Ambiental. 